\title{
A Network of Phosphate Starvation and Immune-Related Signaling and Metabolic Pathways Controls the Interaction between Arabidopsis thaliana and the Beneficial Fungus Colletotrichum tofieldiae
}

\author{
Henning Frerigmann, ${ }^{1,2}$ Markus Piotrowski, ${ }^{3}$ René Lemke, ${ }^{3}$ Paweł Bednarek, ${ }^{2,+}$ and Paul Schulze-Lefert ${ }^{1,+}$ \\ ${ }^{1}$ Max Planck Institute for Plant Breeding Research, Department of Plant Microbe Interactions and Cluster of Excellence on Plant \\ Sciences (CEPLAS), D-50829 Cologne, Germany \\ ${ }^{2}$ Institute of Bioorganic Chemistry, Polish Academy of Sciences, 61-704 Poznań, Poland \\ ${ }^{3}$ Lehrstuhl für Molekulargenetik und Physiologie der Pflanzen, Ruhr-Universität Bochum, D-44801 Bochum, Germany
}

Accepted 21 November 2020.

\begin{abstract}
The beneficial root-colonizing fungus Colletotrichum tofieldiae mediates plant growth promotion (PGP) upon phosphate (Pi) starvation in Arabidopsis thaliana. This activity is dependent on the Trp metabolism of the host, including indole glucosinolate (IG) hydrolysis. Here, we show that $C$. tofieldiae resolves several Pi starvation-induced molecular processes in the host, one of which is the downregulation of auxin signaling in germ-free plants, which is restored in the presence of the fungus. Using CRISPR/Cas9 genome editing, we generated an Arabidopsis triple mutant lacking three homologous nitrilases (NIT1 to NIT3) that are thought to link IG-hydrolysis products with auxin biosynthesis. Retained $C$. tofieldiae-induced PGP in nit1/2/3 mutant plants demonstrated that this metabolic connection is dispensable for the beneficial activity of the fungus. This suggests that either there is an alternative metabolic link between IG-hydrolysis products and auxin biosynthesis, or C. tofieldiae restores auxin signaling independently of IG metabolism. We show that $C$. tofieldiae, similar to pathogenic microorganisms, triggers Arabidopsis immune pathways that rely on IG metabolism as well as salicylic acid and ethylene signaling. Analysis of IG-deficient myb mutants revealed that these metabolites are, indeed, important for control of in planta $C$. tofieldiae growth: however, enhanced $C$. tofieldiae biomass does not necessarily negatively correlate with PGP. We show that Pi deficiency enables more efficient colonization of Arabidopsis by $C$. tofieldiae, possibly due to the MYC2-mediated
\end{abstract}

${ }^{\dagger}$ Corresponding authors: P. Schulze-Lefert; schlef@mpipz.mpg.de; and P. Bednarek; bednarek@ibch.poznan.pl

Funding: This work was supported by funding from the Max-PlanckGesellschaft (Max Planck Society) (to P. Schulze-Lefert), European Research Council Advanced Grant ROOTMICROBIOTA (to P. SchulzeLefert), Germany's Excellence Strategy CEPLAS (EXC-2048/1, Project 390686111) (to P. Schulze-Lefert), and the Narodowe Centrum Nauki (National Science Centre) HARMONIA grant (UMO-2015/18/M/NZ1/ 00406) to P. Bednarek.

*The $\boldsymbol{e}$-Xtra logo stands for "electronic extra" and indicates that supplementary materials are published online.

The author(s) declare no conflict of interest.

(c) (1) $\circledast \Theta$ Copyright $(02021$ The Author(s). This is an open access article distributed under the CC BY-NC-ND 4.0 International license. repression of ethylene signaling and changes in the constitutive IG composition in roots.

Keywords: auxin, beneficial fungi, endophytes, fungus-plant interactions, indole glucosinolates, phosphate availability, plant growth promotion, secondary metabolism

Because of its low availability and mobility, phosphate (Pi) is frequently limiting for plant growth and yield. Plants have evolved to cope with limited Pi availability by developing different adaptive mechanisms collectively known as the Pi starvation response (PSR). Activation of the PSR is dependent on a number of different signaling molecules including plant hormones, sugars, peptides, and reactive oxygen species, and is controlled by PSR transcription factors (PHRs) (Chien et al. 2018; Crombez et al. 2019). The PSR brings about modifications of the root system architecture, including inhibition of primary root growth and enhanced lateral root development and root hair formation, which collectively enable more efficient $\mathrm{Pi}$ foraging (Péret et al. 2011). These modifications in root architecture are controlled by local changes in auxin levels and auxin sensitivity that are induced by Pi starvation (Bates and Lynch 1996; Nacry et al. 2005; Pérez-Torres et al. 2008).

The efficiency of Pi foraging can be further increased by conserved symbiotic associations with arbuscular mycorrhizal fungi, whose hyphae can serve as an extension of the plant root system (Parniske 2008). Despite the benefits of association with mycorrhizal fungi, approximately $30 \%$ of plant species, including the Brassicaceae family, have lost the ability to form this symbiotic interaction (Cosme et al. 2018). Experimental evidence, however, suggests that other beneficial microorganisms support such plants in increasing Pi acquisition ability. For instance, the endophytic fungus Colletotrichum tofieldiae has been found to promote the growth of the model plant Arabidopsis thaliana under low Pi availability $(50 \mu \mathrm{M})$, and of tomato and maize under ample Pi supply (Díaz-González et al. 2020; Hiruma et al. 2016). The beneficial outcome of this interaction has been reported to be independent from signaling activated by the phytohormones jasmonate (JA), ethylene, and salicylic acid (SA) but requires the intact PENETRATION2 (PEN2) pathway for indole glucosinolate (IG) metabolism (Bednarek et al. 2009; Hiruma et al. 2016). Glucosinolates are amino-acid-derived thioglucosides that are produced 
constitutively by species from the Brassicales order (Halkier and Gershenzon 2006). These specialized metabolites have been shown to contribute to protecting Brassicales plants from different pests, including herbivorous insects and pathogenic microorganisms (Hopkins et al. 2009; Pastorczyk and Bednarek 2016). Intact glucosinolates are not biologically active; however, hydrolysis of these metabolites by $\beta$-thioglucosidases (myrosinases) results in the formation of a number of chemically reactive and biologically active metabolites (Wittstock et al. 2016).

In Arabidopsis, glucosinolates are biosynthesized primarily from methionine (aliphatic glucosinolates [AGs]) and from tryptophan (IGs). The two classes of glucosinolates differ not only in their precursor and side chain structure but also in their biological functions. For instance, IGs but not AGs are metabolized by the PEN2 myrosinase to control entry of different filamentous pathogens into leaf epidermal cells (Pastorczyk and Bednarek 2016). In addition to PEN2, IG function in immunity is dependent on the CYP81F2 P450 monooxygenase that hydroxylates unsubstituted indol-3-ylmethyl glucosinolate (I3M) to form 4-hydroxy-I3M, which is converted by a cognate
$O$-methyltransferase to 4-methoxy-I3M (4MO-I3M) (Bednarek et al. 2009; Clay et al. 2009; Pfalz et al. 2011). Apart from their functions in defense, IGs are also implicated in auxin homeostasis (Malka and Cheng 2017). It has been shown that indole-3acetonitrile (IAN), one of the products of myrosinase-mediated I3M hydrolysis, can be converted by nitrilases (NITs) from the Brassicaceae-specific NIT1 subfamily into indole-3-acetaic acid (IAA), which is the simplest and most abundant form of auxin (Fig. 1) (Lehmann et al. 2017; Normanly et al. 1997; Vorwerk et al. 2001).

The first step in IG biosynthesis is catalyzed by two redundant P450 monooxygenases, CYP79B2 and CYP79B3, which convert tryptophan into indole-3-acetaldoxime (IAOx) (Zhao et al. 2002). In addition to IGs, this intermediate is also a precursor of other specialized indole-type metabolites, including the phytoalexin camalexin and indole-3-carboxylic acid derivatives, which are all important for Arabidopsis immunity (Fig. 1) (Böttcher et al. 2014; Glawischnig et al. 2004; Pastorczyk et al. 2020). Consequently, cyp79b2 cyp79b3 double-mutant plants, which are depleted of all of these Trp derivatives, are highly susceptible to many filamentous plant

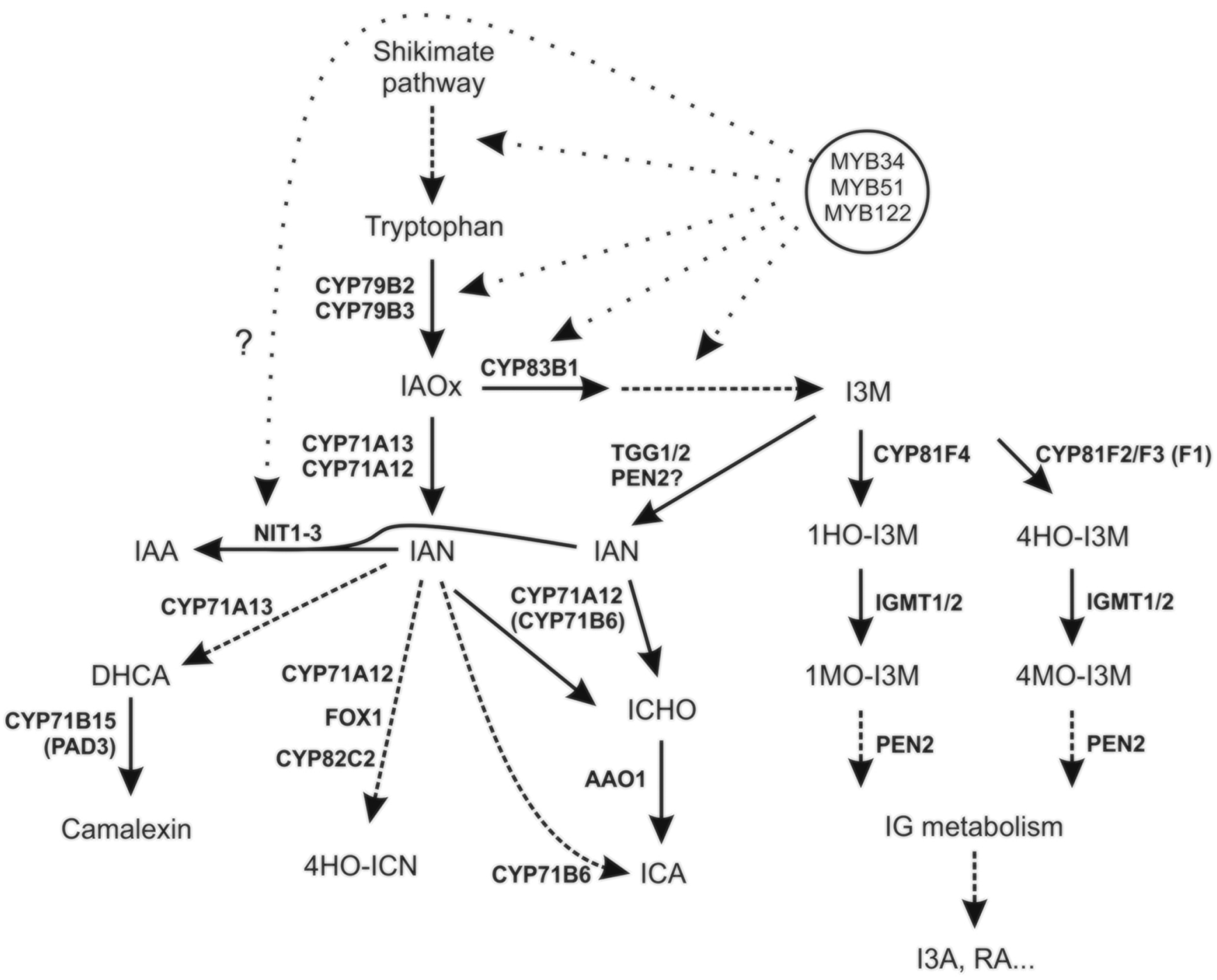

Fig. 1. Biosynthetic links between Trp-derived specialized metabolites and indole-3-acetaic acid (IAA) formation. MYB34-, MYB51-, and MYB122-dependent effect on indole glucosinolate (IG)-related indolic compounds. The figure illustrates the direct regulatory impact of the three HIG-MYB transcription factors (dotted lines) on the biosynthesis of related indolic compounds. Solid lines indicate single enzymatic steps, whereas dashed arrows stand for several enzymatic steps. IAOx $=$ indole3-acetaldoxime, IAN = indole-3-acetonitrile, ICHO = indole-3-carbaldehyde, ICA = indole-3-carboxylic acid, DHCA = R-dihydro-camalexic acid, 4HO-ICN = 4hydroxyindole-3-carbonyl nitrile, $\mathrm{I} 3 \mathrm{M}=$ indole-3-methyl-GSL, 1HO-I3M = 1-hydroxy-I3M, 1MO-I3M = 1-methoxy-I3M, 4HO-I3M = 4-hydroxy-I3M, 4MO-I3M = 4-methoxy-I3M, RA = raphanusamic acid, and I3A = indole-3-methylamine. 
pathogens (Hiruma et al. 2013; Sanchez-Vallet et al. 2010). Moreover, these plants are no longer able to establish beneficial interactions with $C$. tofieldiae, which behaves as a pathogen in this genetic background (Hiruma et al. 2016).

In this study, we investigated the molecular basis underpinning $C$. tofieldiae-induced plant growth promotion (PGP) under low Pi levels in Arabidopsis. Our results indicated that C. tofieldiae-induced PGP strictly correlates with reversion of the PSR. We show that colonization of Arabidopsis roots with $C$. tofieldiae induces changes in auxin signaling but that the biosynthetic link between IGs and IAA is not critical for the outcome of this interaction. Finally, we show that, despite its beneficial effects, $C$. tofieldiae induces immune-related SAand ethylene-dependent responses, as well as IG biosynthesis.

\section{RESULTS}

\section{$P i$ availability and light intensity influence}

\section{C. tofieldiae-dependent PGP.}

We tested C. tofieldiae-induced PGP in Arabidopsis plants grown on an agar matrix using a normal level of inorganic $\mathrm{Pi}$ supply $(625 \mu \mathrm{M} \mathrm{Pi})$ and two different Pi starvation conditions (100 and $50 \mu \mathrm{M} \mathrm{Pi}$, representing moderate and severe Pi deficiency, respectively) under the illumination of 11,250 lx. As reported previously, C. tofieldiae colonization did not increase shoot fresh weight under normal Pi supply. Strikingly, fungal colonization also failed to increase shoot biomass when plants were grown on $50 \mu \mathrm{M}$ Pi (Fig. 2A). A statistically significant increase in shoot fresh weight in $C$. tofieldiae-colonized plants, compared with controls, was observed only when plants were grown on medium containing $100 \mu \mathrm{M} \mathrm{Pi}$ (Fig. 2A). Thus, in our experimental system, $C$. tofieldiae has a clear impact on shoot biomass only under moderate Pi deficiency. In contrast to the concentration-dependent changes in plant fresh weight, we observed a statistically significant $C$. tofieldiae-triggered increase in plant root length under all tested $\mathrm{Pi}$ concentrations (Fig. 2B). To check whether or not PGP correlates with in planta fungal growth, we estimated $C$. tofieldiae biomass in colonized plant tissue by quantifying fungal TUBULIN2 (CtTUB2) in DNA samples isolated from roots of colonized plants. This analysis indicated that fungal biomass was significantly increased in plants grown on media containing $100 \mu \mathrm{M}$ $\mathrm{Pi}$ as compared with $625 \mu \mathrm{M} \mathrm{Pi}$ (Supplementary Fig. S1). When plants were grown on $50 \mu \mathrm{M} \mathrm{Pi}$, we found a greater variation in fungal biomass between the root replicates, which was not significantly different compared with plants grown on $100 \mu \mathrm{M}$ $\mathrm{Pi}$. Therefore, there is no correlation between the extent of C. tofieldiae root colonization and PGP at 100 and $50 \mu \mathrm{M}$ Pi.

To check whether or not $C$. tofieldiae-mediated PGP can also be affected by light conditions, we repeated the same experiment with plants growing under lower light intensities $(3,600$ and 6,800 lx). Subsequent analysis indicated that the relative difference in shoot fresh weight between plants grown under normal or limited Pi decreased with reduced light intensity (Supplementary Fig. S2). Despite this, we were still able to observe statistically significant $C$. tofieldiae-mediated PGP activity when plants were grown on $100 \mu \mathrm{M}$ Pi under 3,600 and 6,800 lx. In contrast to higher light intensities, the lowest light intensity tested induced a significant increase in shoot fresh weight, even in plants grown on $50 \mu \mathrm{M}$ Pi. Overall, this result indicated that, in addition to Pi levels, PGP is also affected by light conditions. Because the highest tested light intensity resulted in the highest fold change in shoot fresh weight, we decided to conduct subsequent experiments under this condition.

\section{DR5::GUS activity}

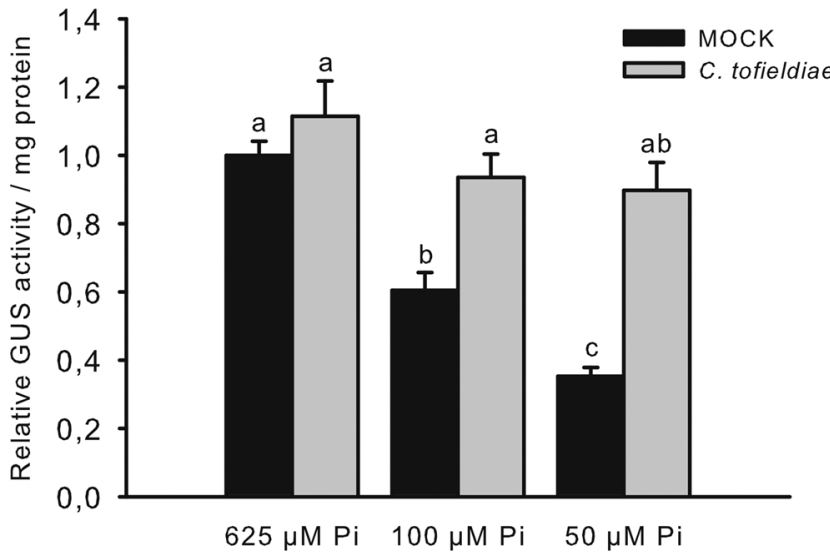

Fig. 3. Colletotrichum tofieldiae is able to restore auxin accumulation upon phosphate $(\mathrm{Pi})$ starvation. Results are means \pm standard error from four independent experiments, each containing three to four biological replicates $(n=15)$. GUS $=\beta$-glucuronidase. Values marked with different letters are significantly different from each other (Kruskal-Wallis test with Bonferroni-corrected $P$ values; $P<0.05$ )
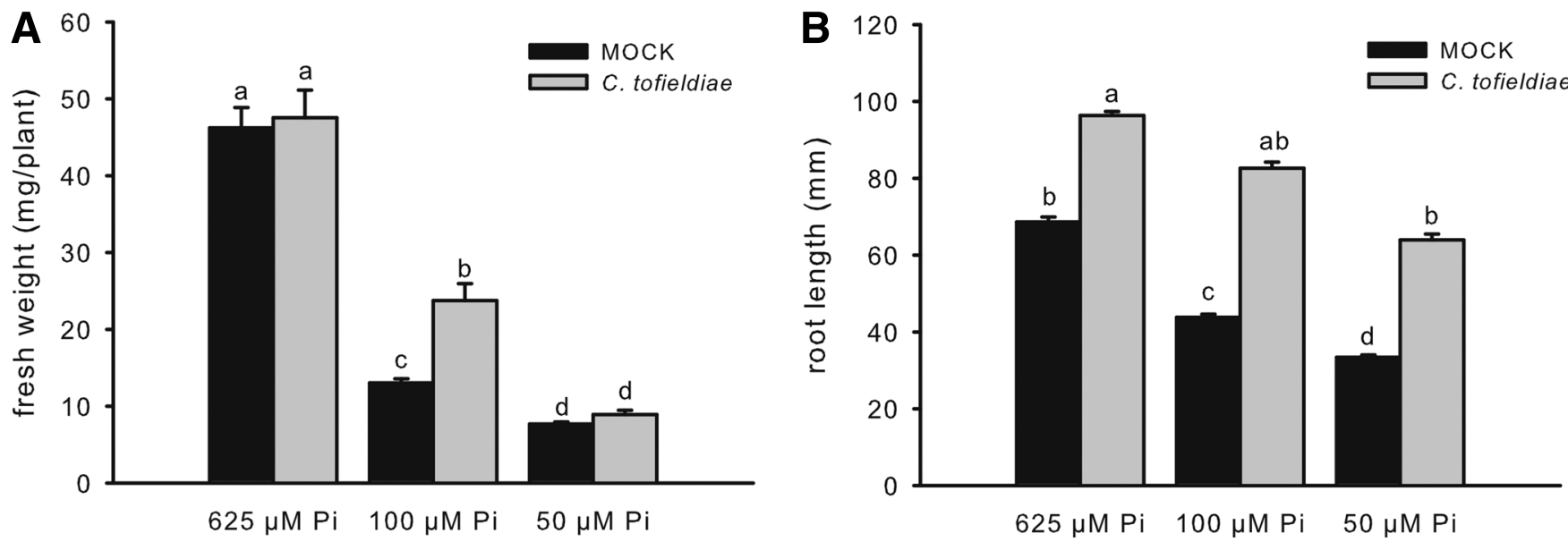

Fig. 2. Colletotrichum tofieldiae-mediated growth promotion is sensitive to phosphate (Pi) levels. A, Fresh weight and B, root length of Arabidopsis thaliana Results are means \pm standard error from four independent experiments, each containing four replicate plates with seven seeds per plate $(n=110)$. Values marked with different letters are significantly different from each other (Kruskal-Wallis test with Bonferroni-corrected $P$ values; $P<0.05$ ). 
Pi starvation-induced IAA depletion is reversed by C. tofieldiae colonization.

Pi starvation induces auxin signaling, which can lead to increased root hair formation (Bates and Lynch 1996; Nacry et al. 2005; Pérez-Torres et al. 2008). We observed that $C$. tofieldiaemediated colonization of Arabidopsis plants grown on $100 \mu \mathrm{M}$ $\mathrm{Pi}$ increased the number and length of root hairs (Supplementary Fig. S3). This suggested that, under Pi-deficient conditions, C. tofieldiae may have an impact on auxin accumulation or auxin signaling. To test this hypothesis, we decided to perform our experiments using a transgenic line expressing $\beta$-glucuronidase (GUS), under the control of the auxin-responsive DR5 synthetic promoter (Ulmasov et al. 1997). Our analysis revealed a clear reduction in total GUS activity in samples obtained from intact $D R 5:: G U S$ seedlings grown on $100 \mu \mathrm{M}$ Pi compared with $625 \mu \mathrm{M} \mathrm{Pi}$. An additional significant drop in GUS activity was observed in seedlings grown on $50 \mu \mathrm{M}$ Pi (Fig. 3). These results showed that Pi starvation significantly dampens auxin accumulation in a dose-dependent manner, indicating lower IAA levels under these conditions. Colonization of roots with $C$. tofieldiae under sufficient Pi supply did not affect GUS activity; however, colonization of roots grown on Pi-deficient media restored GUS activity to the levels observed in plants grown on normal Pi supply (Fig. 3). Overall, these results revealed that the negative impact of Pi starvation on IAA signaling can be reversed by colonization with $C$. tofieldiae.

Trp metabolism but not NIT1 subfamily members influences the interaction between $C$. tofieldiae and Arabidopsis.

The PEN2 myrosinase has been reported to be required for C. tofieldiae-triggered PGP. Thus, we hypothesized that the observed $C$. tofieldiae-induced increase in IAA signaling could be linked to PEN2-mediated IG metabolism (Hiruma et al. 2016). To examine this possibility, we decided to investigate the requirement of three nitrilases (NIT1 to NIT3) from the Brassicaceae-specific NIT1 subfamily, which are thought to catalyze the conversion of I3M-derived IAN into IAA (Fig. 1) for C. tofieldiae-induced PGP. NIT2, NIT1, and NIT3 are organized as a gene cluster on chromosome III (Hillebrand et al. 1998), which hinders the generation of double- and tripleknockout lines by crossing respective single-mutant plants. Therefore, we generated a $\triangle$ NIT1/NIT2/NIT3 triple-knockout line using CRISPR/Cas9. In addition, we used a line in which the expression of NIT1 and NIT2 genes is diminished by RNA interference (hereafter referred to as NIT2 RNAi) (Lehmann
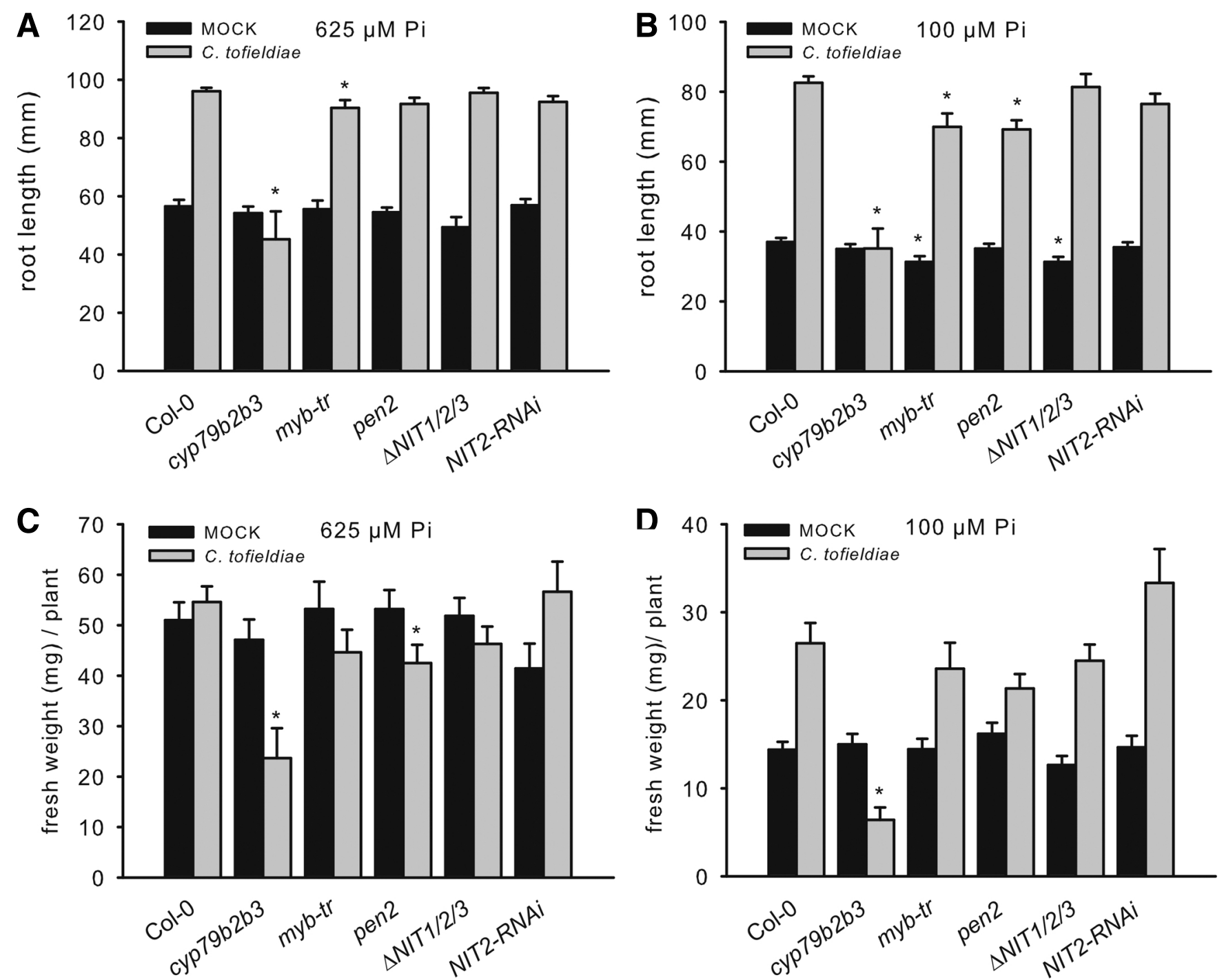

Fig. 4. Diverse mutants in tryptophan secondary metabolism show specific impairment of Colletotrichum tofieldiae-mediated plant growth promotion. A and $\mathbf{B}$, Root length and $\mathbf{C}$ and $\mathbf{D}$, fresh weight. $\mathrm{Pi}=$ phosphate. Results are means \pm standard error from three independent experiments, each containing four replicate plates each $(n=42)$. Values marked with asterisks are significantly different from the respective Col-0 (Student's $t$ test; $P<0.05)$. 
et al. 2017). Using these generated lines, we determined the role of IG metabolism in C. tofieldiae-induced PGP. In these experiments, we also used the pen 2 knockout, IG-deficient $m y b 34$ myb51 myb122 (myb-tr) triple mutant, and the cyp79b2 cyp79b3 (cyp79b2b3) double mutant that is deficient in all IAOx-derived secondary metabolites. Among all of the tested lines, the most striking effect on plant growth was observed in the cyp $79 b 2 b 3$ plants. In this case, growth of approximately $95 \%$ of $C$. tofieldiae-inoculated seedlings ceased with fungal overgrowth, detectable already at the very early developmental stages. The seedlings that survived this stage and remained alive at the age of 4 weeks were not only significantly smaller than the C. tofieldiae-colonized wild-type (WT) plants but also smaller in size than the respective mock-treated plants (Fig. 4C and D). In addition, cyp $79 b 2 b 3$ was the only tested line in which colonization with $C$. tofieldiae did not increase root length (Fig. 4A and B). Overall, this result indicated that lack of IAOx-derived metabolites not only interferes with $C$. tofieldiaeinduced PGP but also leads to an additional growth penalty during interaction with $C$. tofieldiae. As indicated by our quantitative PCR (qPCR) analysis, this growth defect clearly correlated with increased $C$. tofieldiae biomass in the surviving cyp79b2b3 mutant plants compared with WT plants (Fig. 5A). Other tested mutants, including $\triangle N I T 1 / 2 / 3$ and NIT2 RNAi, were not defective in the $C$. tofieldiae-induced PGP (Fig. 4D). The $m y b$-tr and pen 2 mutations resulted in slight but significant reductions in the length of $C$. tofieldiae-colonized roots on $100 \mu \mathrm{M}$ Pi (Fig. 4B). Notably, although PGP was WT like, the $m y b$-tr mutation led to elevated $C$. tofieldiae biomass in colonized plants grown on $100 \mu \mathrm{M}$ Pi (Fig. 5A), suggesting that increased fungal growth does not necessarily negatively affect plant performance.

Although there was no clear reduction in shoot fresh weight, we observed that some of the $C$. tofieldiae-inoculated pen 2 and $m y b$-tr seedlings did not survive the early stages of development, similar to many of the cyp $79 b 2 b 3$ seedlings. To estimate the contribution of these nonsurviving seedlings to plant yield, we measured total dry weight of seedlings per plate (Fig. 5B). This indicated a significant drop in the total dry weight of pen2 and $m y b$-tr compared with WT seedlings. However, similar to the shoot fresh weight, we did not observe any differences between WT and $\triangle N I T 1 / 2 / 3$ or NIT2 RNAi plants (Fig. 5).

Prompted by the lack of growth defects in tested nitrilase mutants, we checked how $\mathrm{Pi}$ levels and interaction with C. tofieldiae affect expression of the three members of the NITI subfamily. Earlier RNA sequencing analysis performed in an experimental system similar to that used in this study indicated that Pi level does not significantly affect expression of these three genes in roots, whereas NITI expression is downregulated during colonization with $C$. tofieldiae (Hacquard et al. 2016). Our reverse-transcription (RT)-qPCR analysis of samples prepared from whole seedlings revealed that NIT1 expression is significantly affected by neither $\mathrm{Pi}$ concentrations nor plant colonization with $C$. tofieldiae (Fig. 6A). In contrast to NIT1, expression of NIT2 and NIT3 was significantly increased by $\mathrm{Pi}$ starvation in intact seedlings and this increase was reversed by C. tofieldiae colonization (Fig. 6B and C). Together, these results negatively correlated with the observed changes in GUS activity in DR5::GUS plants (Fig. 3), suggesting that NIT1, NIT2, and NIT3 are dispensable for the reversion of IAA accumulation in $C$. tofieldiae-colonized roots. Overall, our analyses as well as earlier results (Hacquard et al. 2016) do not support a link between NIT-mediated conversion of I3M to IAA, and $C$. tofieldiae-induced PGP.

\section{Impact of $C$. tofieldiae on IG accumulation resembles that of plant pathogens.}

To obtain more detailed insight into the function of glucosinolates in the PGP, we investigated how Pi availability and interaction with $C$. tofieldiae affects accumulation of these compounds. Our high-performance liquid chromatography (HPLC) analysis revealed that Pi deficiency significantly increases total AG and IG accumulation in shoots (Fig. 7A). The observed change in total IG levels was associated with elevated accumulation of all compounds included in this group (Fig. 7B). In contrast to shoots, in roots, Pi deficiency did not affect the accumulation of AGs (Fig. 7C). In this organ, we also did not observe any significant differences between IG levels at 625 and $100 \mu \mathrm{M}$ Pi. Only at a Pi level of $50 \mu \mathrm{M}$ did we observe slightly reduced total IG levels, which was specifically
A

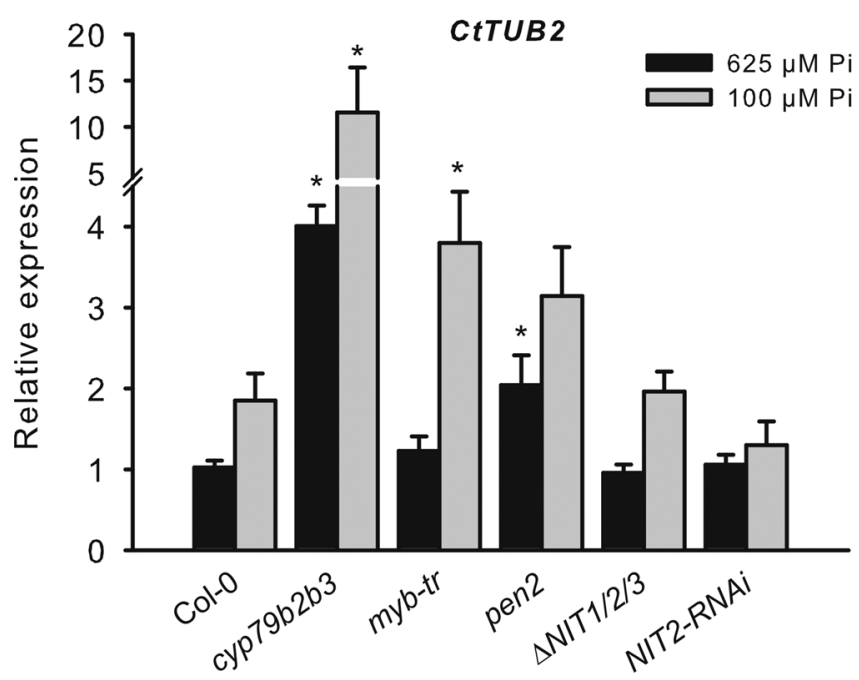

B

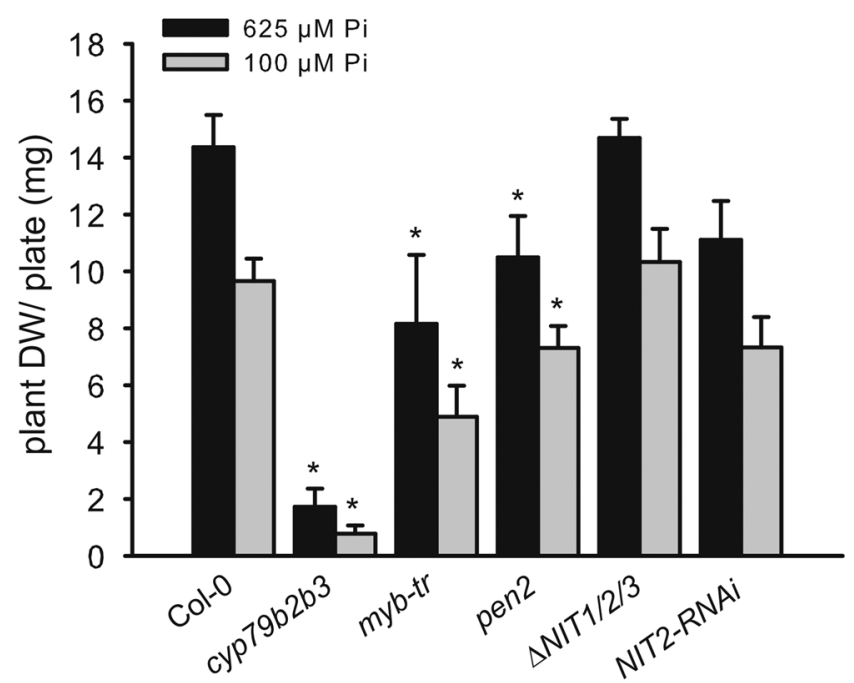

Fig. 5. Nitrilase mutants show no impairment in Colletotrichum tofieldiae-mediated plant growth promotion. A, Fungal growth and B, dry weight (DW) per plate. $\mathrm{Pi}=$ phosphate. Results are means \pm standard error from three independent experiments containing three or four replicates each $(n=9$ and 12 for $\mathrm{A}$ and $\mathrm{B}$, respectively). Values marked with asterisks are significantly different from the respective Col- 0 (Student's $t$ test; $P<0.05$ ). 
associated with a drop in the accumulation of 4MO-I3M and, particularly, 1MO-I3M (Fig. 7C and D).

Our analysis did not reveal any clear impact of $C$. tofieldiae colonization on AG accumulation in shoots and roots (Fig. 7A and $\mathrm{C}$ ). However, colonization with the fungus under $\mathrm{Pi}$ deficient conditions had a significant impact on IG levels, particularly on the accumulation of $4 \mathrm{MO}-\mathrm{I} 3 \mathrm{M}$, which was induced by $C$. tofieldiae in roots and shoots of plants grown on 100 and $50 \mu \mathrm{M}$ Pi (Fig. 7). In addition, we observed a significant reduction of $\mathrm{I} 3 \mathrm{M}$ levels in shoots of colonized plants grown on $100 \mu \mathrm{M} \mathrm{Pi}$ compared with the respective mock samples. Unlike I3M and 4MO-I3M, 1MO-I3M levels were not affected by $C$. tofieldiae colonization (Fig. 7B and D). Overall, the observed $C$. tofieldiae-induced changes in IG accumulation resembled those reported in pathogen-inoculated leaves (Pastorczyk and Bednarek 2016), suggesting that the IG biosynthetic pathway responds similarly to pathogenic and beneficial fungi.

\section{Colonization of Arabidopsis with C. tofieldiae reverses PSR and induces immune responses.}

Our analysis revealed that colonization with $C$. tofieldiae can reverse, completely or partially, Pi deficiency-induced changes in IAA signaling, and NIT2 and NIT3 expression in intact seedlings (Figs. 3 and 6B and C). For this reason, we decided to test whether colonization with $C$. tofieldiae can generally reverse the PSR in Arabidopsis. To this end, we investigated the expression profile of the Pi starvation marker genes, including two noncoding RNAs (IPS1 and miR399D) (Franco-Zorrilla et al. 2007; Fujii et al. 2005) and AtPT1, which encodes a Pi transporter (Muchhal et al. 1996). As shown by Hacquard et al. (2016), the expression of IPS1 but not of miR399D and AtPTI can be significantly downregulated in roots during $C$. tofieldiae colonization under low Pi levels. Our RT-qPCR analysis performed on RNA samples isolated from intact seedlings indicated that both of the noncoding RNAs were upregulated at 100 and $50 \mu \mathrm{M} \mathrm{Pi}$, whereas the expression of AtPT1 was upregulated only at $50 \mu \mathrm{M}$ compared with $625 \mu \mathrm{M}$ Pi (Fig. 6D, $\mathrm{E}$, and F). Of note, colonization with $C$. tofieldiae partially reversed transcriptional activation not only of IPS1 but also of miR399D at $50 \mu \mathrm{M}$ Pi (Fig. 6D and E). However, similarly to Hacquard et al. (2016), we did not observe a clear impact of C. tofieldiae colonization on AtPT1 expression (Fig. 6F).

Because Pi deficiency induces the JA signaling pathway (Khan et al. 2016), we became interested in the expression of the JA-responsive gene $V S P 2$, and of PDF1.2, which is activated synergistically by both JA and ethylene (Liu et al. 2005; Zarei et al. 2011). In contrast to the analysis performed in roots (Hacquard et al. 2016), we found that, in intact seedlings, the expression of VSP2 was clearly enhanced under Pi deficiency, which confirms activation of JA signaling under our experimental conditions (Fig. 6I). Moreover, in accordance to the behavior of the tested PSR markers, this was reversed in the presence of C. tofieldiae (Fig. 6I). In contrast to VSP2,
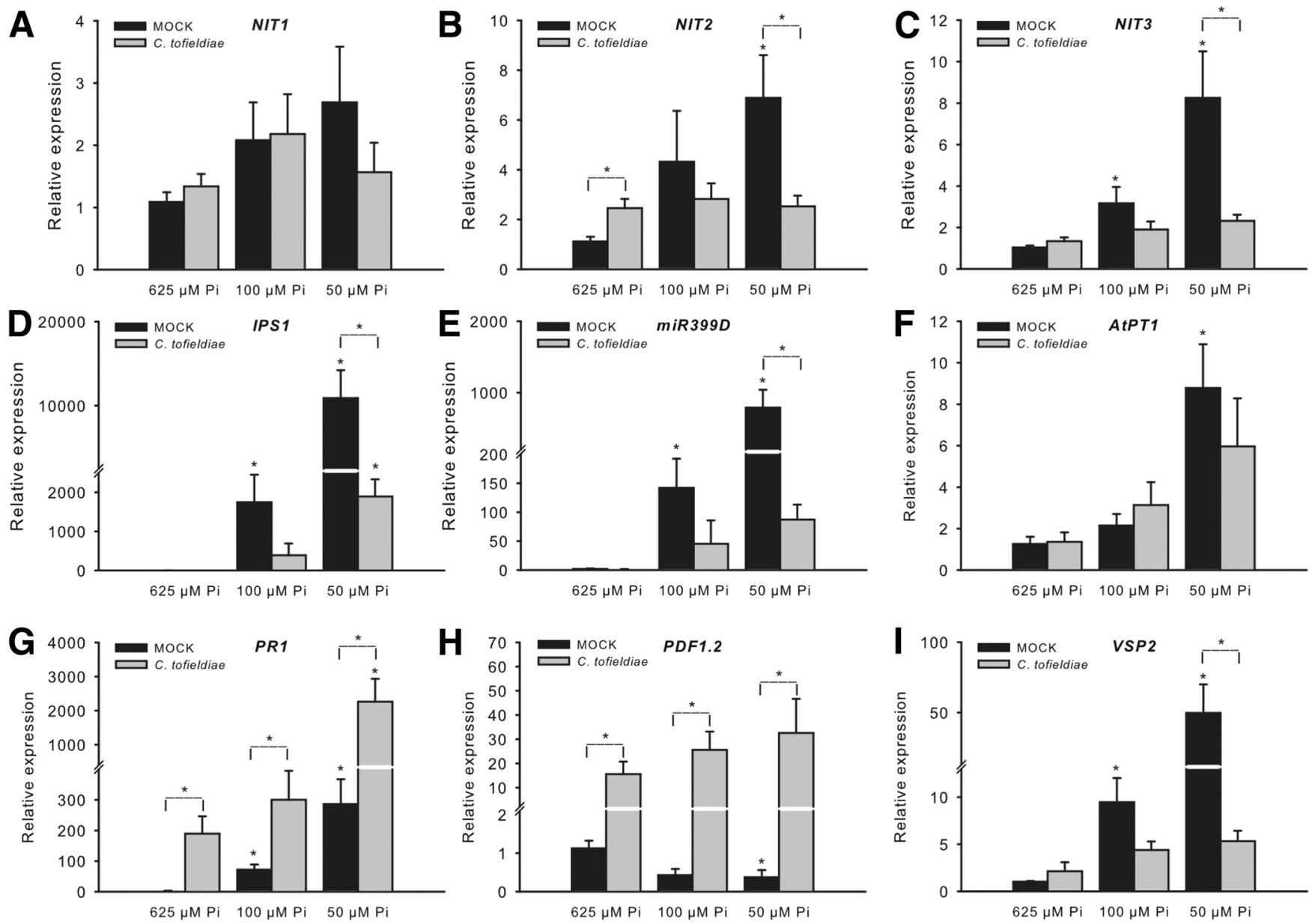

Fig. 6. Cocultivation with Colletotrichum tofieldiae reverses phosphate (Pi) starvation response-mediated changes in gene expression. Relative expression of selected genes measured in samples prepared from intact seedlings. Presented results are means \pm standard error from three independent experiments, each containing three biological replicates $(n=9)$. Values marked with asterisks are significantly different from the respective Col-0. Differences between mock and C. tofieldiae cocultivation at specific Pi concentrations are also indicated with asterisks (Student's $t$ test; $P<0.05$ ). 
expression of $P D F 1.2$ was significantly downregulated at $50 \mu \mathrm{M}$ Pi compared with $625 \mu \mathrm{M}$ Pi (Fig. $6 \mathrm{H}$ ). The presence of C. tofieldiae not only reversed PDF1.2 expression to the levels observed under normal Pi supply but also strongly upregulated expression of this marker gene under all tested Pi concentrations. Interestingly, PDF1.2 expression was below the detection limit in roots, despite Pi-limiting conditions and $C$. tofieldiae colonization (Hacquard et al. 2016), suggesting that the changes in expression of this gene observed in our analysis (Fig. $6 \mathrm{H}$ ) occur predominantly in leaves. The upregulation of PDF 1.2 could be mediated by an increase in ethylene levels resulting from the defense response triggered by $C$. tofieldiae. In accordance with this assumption, we observed that C. tofieldiae colonization abolished $\mathrm{Pi}$ starvation-triggered anthocyanin accumulation in leaves, which has been reported to be negatively regulated by ethylene (Lei et al. 2011) as well as positively regulated by JA (Khan et al. 2016) (Supplementary Fig. S4). Finally, we determined expression of the PRI gene, which is a marker of the SA signaling pathway. Similar to $P D F 1.2$, expression of this gene was below the detection limit in roots under analogous experimental conditions (Hacquard et al. 2016). Our analysis carried out with samples prepared from intact seedlings indicated that expression of PRl was
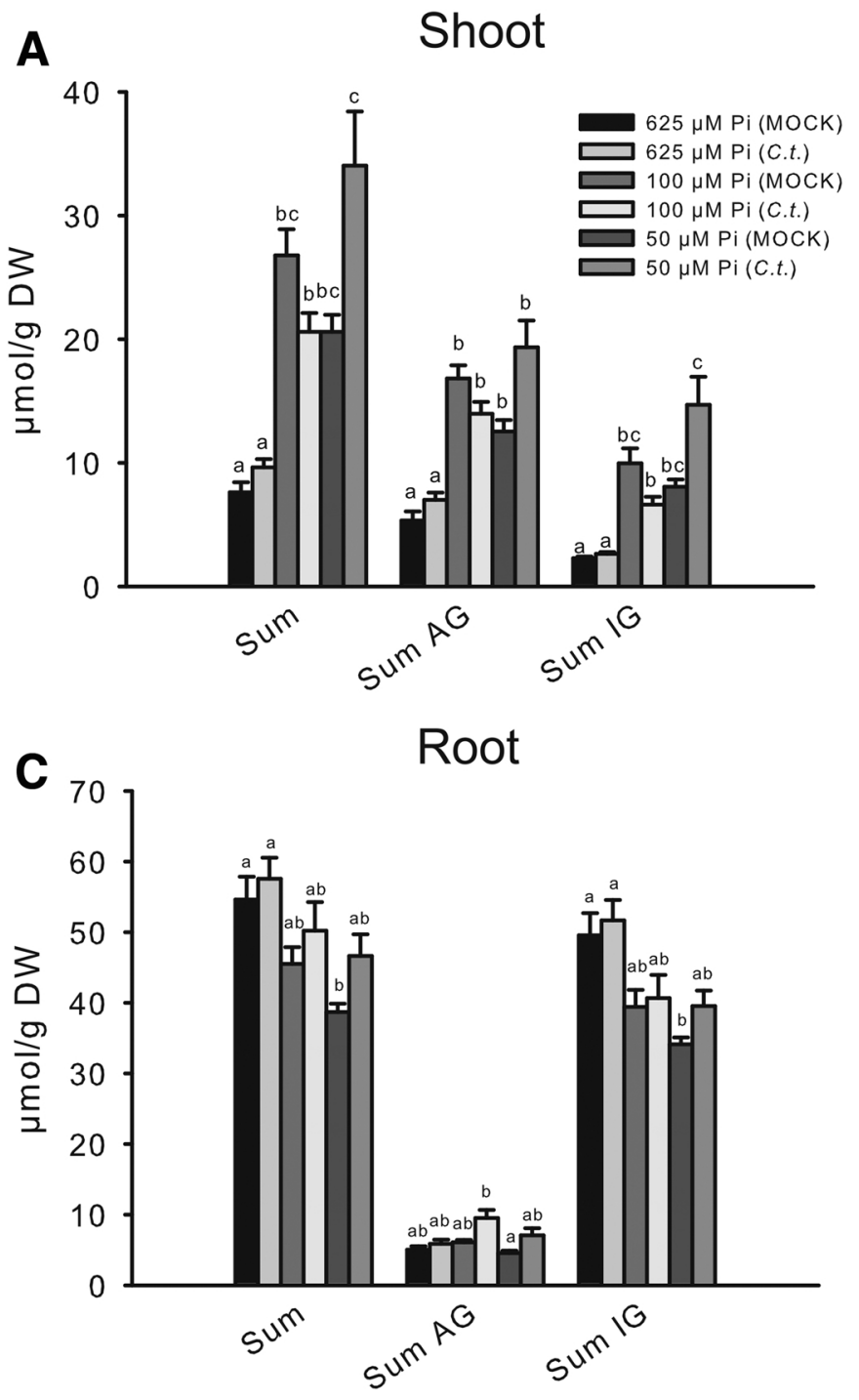

clearly upregulated in response to Pi deficiency, which could reflect the reported impact of Pi availability on the accumulation of SA (Pant et al. 2015; Prerostova et al. 2018). However, instead of reversing $P R 1$ transcription, cocultivation with $C$. tofieldiae led to a further significant increase in the expression of this gene, indicating that SA-dependent immune responses are induced during the interaction with $C$. tofieldiae. Overall, our analysis revealed that colonization with $C$. tofieldiae, at least partially, reverses PSR-related signaling in Arabidopsis. However, in the case of SA and ethylene signaling pathways that are involved in both the response to Pi starvation and plant immunity, this reversion overlaps with $C$. tofieldiaemediated induction of the expression of the respective genes.

\section{DISCUSSION}

In this study, we investigated the molecular mechanism underlying C. tofieldiae-induced PGP in Arabidopsis. Our results indicate that colonization of Arabidopsis plants with C. tofieldiae under Pi-deficient conditions resolves the PSR. This PSR resolution is characterized by a downregulation of two $\mathrm{Pi}$ starvation-responsive noncoding RNAs, IPS1 and miR399D; the JA-responsive VSP2 gene; and NIT2 and NIT3,
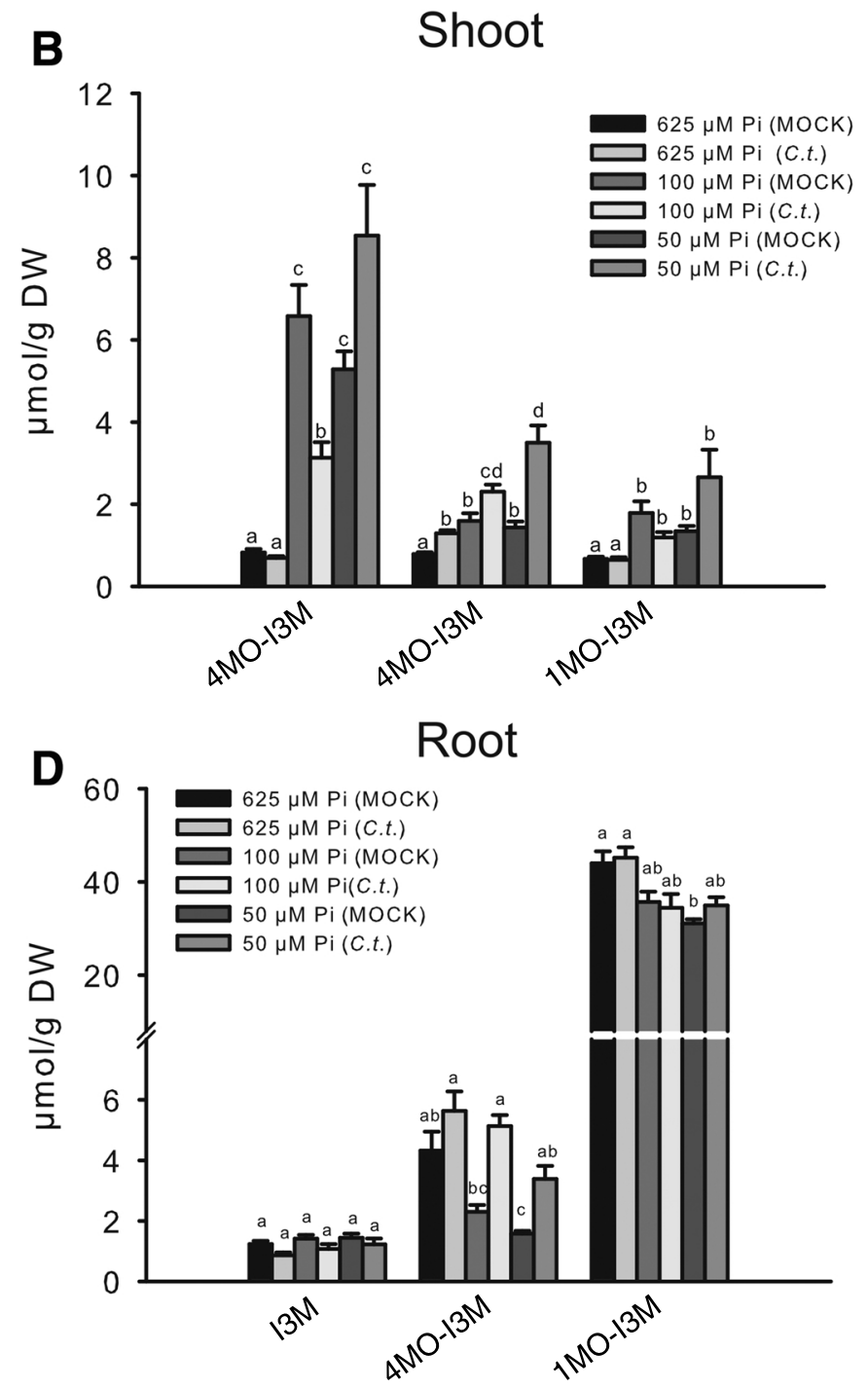

Fig. 7. Specific effects of Colletotrichum tofieldiae cocultivation on glucosinolate accumulation at different phosphate (Pi) concentrations. Results are means \pm standard error from $\mathbf{A}$ and $\mathbf{B}$, four or $\mathbf{C}$ and $\mathbf{D}$, three independent biological replicates $(n=16$ or 9 , respectively). DW $=$ dry weight, AG $=$ aliphatic glucosinolate, $\mathrm{IG}=$ indole glucosinolate, $\mathrm{I} 3 \mathrm{M}=$ indol-3-ylmethyl glucosinolate, 4MO-I3M = 4-methoxy-I3M, and 1MO-I3M = 1-methoxy-I3M. Values marked with different letters are significantly different from each other (Kruskal-Wallis test with Bonferroni-corrected $P$ values; $P<0.05$ ). 
observed in intact seedlings (Fig. 6B to E and I). Considering that a similarly significant reversion of gene expression was observed in roots only for IPS1 (Hacquard et al. 2016), interestingly, this phenomenon also occurs in leaves that are not directly associated with $C$. tofieldiae. In addition, colonization with $C$. tofieldiae restored IAA signaling in plants grown under low Pi availability (Fig. 3). Resolution of the PSR response corresponded with PGP in plants grown at moderate $(100 \mu \mathrm{M})$ Pi but not at severe $(50 \mu \mathrm{M}) \mathrm{Pi}$ deprivation. As exemplified for IPS1 expression, the observed lack of PGP at the lower Pi concentration correlated with a stronger PSR response compared with plants grown at moderate $\mathrm{Pi}$, which was not always completely reversed by $C$. tofieldiae. Additionally, the expression of AtPT1 was higher at severe compared with moderate $\mathrm{Pi}$ deficiency, and this change was not significantly reversed by $C$. tofieldiae colonization. In contrast to the differences in PGP and in the PSR markers, we did not observe significant changes in the $C$. tofieldiae biomass between moderate and severe Pi deprivation (Supplementary Fig. S1), indicating that the capacity of Arabidopsis to control $C$. tofieldiae growth in planta is similar at both tested Pi concentrations. Overall, these findings suggest that lack of PGP at $50 \mu \mathrm{M}$ Pi results from a stronger Pi deficiency that could not be fully compensated for by the interaction with $C$. tofieldiae, rather than from fungal overgrowth that could negatively impact plant growth under this specific condition. Thus, within the tested Pi gradient $(625,100$, and $50 \mu \mathrm{M})$, beneficial activity of C. tofieldiae on Arabidopsis growth under our experimental conditions is limited to a $\mathrm{Pi}$ stress optimum. Consequently, C. tofieldiae-mediated PGP is not observed at both extremes of the gradient.

In addition to the expression of PSR markers, Pi deficiency has a strong impact on the biosynthesis of glucosinolates. This was particularly obvious in the shoots of tested plants, which accumulated significantly higher amounts of AGs and IGs (Fig. 7A). These elevated glucosinolate levels are in accordance with an earlier study that revealed enhanced accumulation of selected glucosinolates in shoots and roots of Arabidopsis plants grown under Pi deficiency (Pant et al. 2015). However, this inverse relationship between $\mathrm{Pi}$ status and glucosinolate accumulation is not unique for these compounds because it was also observed for other secondary metabolites, including different types of phenylpropanoids. In contrast to the study of Pant et al. (2015), in our experiments, total glucosinolate levels were only weakly affected in roots, suggesting that, in addition to Pi deficiency, other factors are necessary to increase glucosinolate accumulation in this organ. The biological significance of elevated accumulation of different types of metabolites, including glucosinolates, under Pi starvation remains unclear. It has been shown that these changes are mediated predominantly by the MYB transcription factor PHOSPHATE STARVATION RESPONSE 1 (PHR1) with minor, if any, contribution of the E2 conjugase PHOSPHATE2 and miR399 (Pant et al. 2015). However, because the phrl mutant still benefited from colonization with $C$. tofieldiae under Pi starvation (Hiruma et al. 2016), the observed Pi-dependent changes in secondary metabolite accumulation seem to be dispensable for PGP under these conditions.

Our experiments indicate that, apart from the Pi status, accumulation of IGs is also affected during the interaction with C. tofieldiae (Fig. 7). These changes mirror those observed during colonization of Arabidopsis leaves with biotrophic and necrotrophic fungal pathogens, and include elevated accumulation of $4 \mathrm{MO}-\mathrm{I} 3 \mathrm{M}$, the formation of which is mediated by the CYP81F2 monooxygenase and cognate methyltransferases (Bednarek et al. 2009; Pastorczyk and Bednarek 2016; Pfalz et al. 2011). This is also in accordance with an earlier study on the interaction of Arabidopsis with the sebacinoid rootassociated fungi Piriformospora indica and Sebacina vermifera (Lahrmann et al. 2015). Collectively, these observations suggest similarities between the mechanisms of IG metabolization involved in controlling the growth of pathogenic and beneficial microorganisms. In line with this assumption, analysis of PGP and C. tofieldiae biomass in a series of mutants defective in Trp and IG metabolism indicated that the end products of these pathways are synergistically controlling the impact of C. tofieldiae on Arabidopsis growth, as well as in planta development of this fungus (Figs. 4 and 5) (Hiruma et al. 2016). In this context, it is instructive that $\mathrm{Pi}$ starvation reduced the accumulation of 4MO-I3M in roots (Fig. 7D), suggesting that, under Pi deficiency, plants curtail constitutive chemical defense to increase the chance of colonization with a beneficial root-colonizing microbe, which could help the host acquire this nutrient. However, analysis of the cyp81f2 mutant plants revealed that, in contrast to the interaction with leaf-infecting pathogens, CYP81F2 is not essential for limiting colonization of Arabidopsis with $P$. indica and $S$. vermifera (Lahrmann et al. 2015). This suggests that $4 \mathrm{MO}-\mathrm{I} 3 \mathrm{M}$ is dispensable for controlling the growth of beneficial fungi, or that another root-specific CYP81F isoform is important for mediating microbe-triggered production of this modified IG in roots. The possible isoform candidates are CYP81F3, which catalyzes the respective I3G substitution and exhibits a root-specific expression pattern, and CYP81F1, the function of which remains unclear (Fig. 1) (Pfalz et al. 2011).

In addition to the toxic end products, which may affect fungal growth, unstable aglycones formed during the myrosinasemediated hydrolysis of glucosinolates can decompose to nitriles whose formation is supported by specifier proteins (Wittstock et al. 2016). Consequently, hydrolysis of I3M may lead to the formation of IAN, which can be further converted to IAA by the activity of NIT1 to NIT3 (Fig. 1) (Janowitz et al. 2009; Lehmann et al. 2017). We initially hypothesized that C. tofieldiae-induced PGP in Arabidopsis may be linked to changes in auxin signaling. As indicated by our analysis of DR5::GUS plants, Pi starvation reduced auxin levels, and this was at least partially restored upon $C$. tofieldiae colonization (Fig. 3). Combining this observation with the earlier report on the requirement of PEN2 myrosinase for $C$. tofieldiae-induced PGP (Hiruma et al. 2016), we hypothesized that PEN2mediated IG hydrolysis contributes to IAA biosynthesis. However, $\triangle N I T 2 / N I T 1 / N I T 3$ and NIT2 RNA $i$ lines did not reveal defects in PGP, suggesting that either the observed C. tofieldiae-mediated changes in auxin accumulation originate from another source or these changes are dispensable for the C. tofieldiae-induced PGP. This also indicated that the impact of PEN2 on the PGP, as well as on pathogen biomass, stems from its role in the formation of glucosinolate catabolic products other than IAA. The changes in auxin signaling observed during the interaction with $C$. tofieldiae could be due to canonical IAA biosynthesis or to the pathway that involves indole-3-acetamide hydrolase AMI1 and has been hypothesized to branch from IAOx (Lehmann et al. 2010; Mano and Nemoto 2012). However, many pathogenic and endophytic microorganisms produce plant hormones, or their functional analogs, to manipulate host metabolic status to their advantage (Chanclud and Morel 2016). A few Colletotrichum spp. have also been shown to be capable of producing IAA (Lu et al. 2000; Maor et al. 2004; Numponsak et al. 2018; Robinson et al. 1998). To test whether $C$. tofieldiae has this ability, we performed liquid chromatography-mass spectrometry analysis of extracts prepared from $C$. tofieldiae hyphae, cultivated on potato dextrose agar (PDA) (not shown). This did not reveal IAA production; however, it cannot be excluded that $C$. tofieldiae is able to 
synthesize IAA under different growth conditions (e.g., in planta). Overall, we cannot conclude at present whether the observed changes in auxin accumulation are related to IAA pools produced by the plant or by the fungus.

Our gene expression analysis revealed strong induction of $P R I$ and $P D F 1.2$ transcription in C. tofieldiae-colonized plants at all tested Pi concentrations (Fig. 6G and $\mathrm{H}$ ). These transcriptional changes suggest that, in addition to IG metabolism, colonization of Arabidopsis with $C$. tofieldiae triggers other immune pathways, including those dependent on SA and ethylene signaling. Notably, the expression of $P R 1$ and $P D F 1.2$ remained below the detection level in roots under similar experimental conditions (Hacquard et al. 2016), indicating that the changes observed here in the expression of both genes occur in leaves. This may explain why, as the WT-like PGP in the ein2 sid2 dde2 pad4 quadruple mutant indicates, hormone signaling pathways are not crucial in controlling the interaction between Arabidopsis and $C$. tofieldiae, which predominantly colonizes roots (Hiruma et al. 2016). In contrast to SA and ethylene pathways, expression levels of VSP2 (Fig. 6I) indicated that, depending on the Pi supply levels, JA signaling is either not affected or even suppressed in the presence of $C$. tofieldiae, which is in accordance with crosstalk between these pathways limiting fitness costs associated with defense (Vos et al. 2015). Constantly elevated $V S P 2$ expression at 100 and $50 \mu \mathrm{M}$ Pi indicated that, consistent with an earlier report, JA-dependent defense pathways are constitutively activated under Pi starvation which, in turn, may affect the interaction of plants with other organisms (Khan et al. 2016). The JA hormone is usually considered to be important in plant defenses against herbivores but not against microbial pathogens. However, mutation in the JA-activated MYC2 transcription factor releases the JA-dependent repression of ETHYLENE RESPONSE FACTOR1, which is positively regulated by ethylene, leading to higher expression of $P D F 1-2$ and a higher resistance against necrotrophic pathogens, as shown for Botrytis cinerea (Cagnola et al. 2018; Song et al. 2014). To examine whether lack of functional MYC2 could also affect interaction with beneficial microbes, we analyzed $C$. tofieldiae biomass in the myc2 mutant grown on 625 and $100 \mu \mathrm{M} P \mathrm{Pi}$ (Supplementary Fig. S5). We did not observe any impact of myc2 mutation on $C$. tofieldiae growth at high Pi but, at $100 \mu \mathrm{M} \mathrm{Pi}$, fungal growth in $m y c 2$ plants was reduced compared with WT plants. This indicates similar contributions of the MYC2dependent branch of JA signaling to interactions with necrotrophic pathogens and beneficial fungi under low Pi supply.

\section{MATERIALS AND METHODS}

\section{Arabidopsis loss-of-function and gain-of-function mutants used in this study.}

The A. thaliana loss-of-function and gain-of-function mutants used in this study are all in the Columbia- 0 (Col-0) genetic background. Most loss-of-function mutants have already been described: cyp79B2/B3 (Zhao et al. 2002), pen2-2 (Lipka et al. 2005), myb-tr (Frerigmann and Gigolashvili 2014b), and myc2/jin1.9 (Dombrecht et al. 2007). NIT2-RNA $i$ was described by Lehmann et al. (2017) and DR5::GUS by Ulmasov et al. (1997). The $\Delta N I T 2 / 1 / 3$ line was generated by CRISPR/Cas9, as described below.

\section{Generation of $\Delta N I T 2 / 1 / 3$ deletion plants by CRISPR/Cas9.}

The CRISPR/Cas9 construct for the deletion of the NIT2/NIT1/NIT3 gene cluster on A. thaliana chromosome 3 was made in pKSE401 (Lowder et al. 2015). The target sequence (underlined) TGCTATTTGCTGGGAGAATAGG (the last three bases represent the PAM site) is located at the $3^{\prime}$ end of exon 3 in all three NITl homologs, and contains the coding sequence for the catalytically active cysteine (Supplementary Fig. S6). Forward primer 5'ATTGTGCTATTTGCTGGGAGAAT3' and reverse primer 5'AAACATTCTCCCAGCAAATAGCA3' were hybridized to produce a double-stranded DNA with 5' ATTGand AAAC overhangs, respectively, which was subsequently ligated into a $B s a \mathrm{I}$-hydrolyzed pKSE401 plasmid, thereby removing a streptomycin resistance cassette and establishing a single-guide RNA containing the target sequence. The construct (pKSE401_NIT213_1) was verified by DNA sequencing.

Agrobacterium tumefaciens strain GV3101 was transformed with pKSE401_NIT213_1 by electroporation, and used for transformation of six individual plants of Arabidopsis thaliana ecotype Col-0 by the floral-dip method (Clough and Bent 1998). Kanamycin-resistant T1 plants (up to 10 individuals of each transformed T0 plant) were tested for deletions within the NIT2/NIT1/NIT3 gene cluster by PCR. Although some plants were positive for a NIT2/NITI/NIT3 deletion (as indicated by the occurrence of a short NIT2-NIT3 PCR product; for primer sequences see Supplementary Table S1), these plants proved to be mosaic. T2 seedlings were preselected on Gamborg B5 medium containing $30 \mu \mathrm{M}$ IAN, which allows for the screening of a nonfunctional NIT1 gene: nitl plants are resistant against IAN, while WT (NIT1) plants show a typical auxin phenotype (Normanly et al. 1997). IAN-resistant plants were again analyzed by PCR and one plant was identified which was positive for a NIT2/NIT1/NIT3 deletion, and in which none of the single NIT1, NIT2, and NIT3 genes could be amplified. Sequence analysis confirmed that the whole chromosomal fragment between the sites targeted by Cas 9 cleavage in the NIT2 and NIT3 genes (approximately 10,300 bases, including the last two exons of NIT2 gene, the whole NIT1 gene, and the first three exons of the NIT3 gene) was removed with the concomitant addition of a single T residue (Supplementary Fig. S6B). The progeny of this plant (T3 generation) showed the same genotype, were resistant to IAN, and showed no NIT1/NIT2/NIT3 protein by Western blotting (Supplementary Fig. S6C) and no nitrilase activity with the substrate 6-heptenenitrile (Supplementary Fig. S6D). Resistance to IAN, Western blotting, and activity assays were performed as described by Lehmann et al. (2017).

\section{Fungal cocultivation with Arabidopsis.}

Three different media were used for cocultivation of fungus with Arabidopsis, one with high $\mathrm{Pi}(625 \mu \mathrm{M} \mathrm{Pi})$, and two with low Pi (100 or $50 \mu \mathrm{M} \mathrm{Pi})$. Agar plates were prepared with halfstrength Murashige and Skoog medium $(750 \mu \mathrm{M} \mathrm{MgSO}$, $625 \mu \mathrm{M} \mathrm{KH}_{2} \mathrm{PO}_{4}, 10.3 \mathrm{mM} \mathrm{NH}_{4} \mathrm{NO}_{3}, 9.4 \mathrm{mM} \mathrm{KNO}_{3}, 1.5 \mathrm{mM}$ $\mathrm{CaCl}_{2}, 55 \mathrm{nM} \mathrm{CoCl}_{2}, 53 \mathrm{nM} \mathrm{CuCl}_{2}, 50 \mu \mathrm{M} \mathrm{H}_{3} \mathrm{BO}_{3}, 2.5 \mu \mathrm{M} \mathrm{KI}$, $50 \mu \mathrm{M} \mathrm{MnCl}, 520 \mathrm{nM} \mathrm{Na} \mathrm{MoO}_{4}, 15 \mu \mathrm{M} \mathrm{ZnCl} 2,75 \mu \mathrm{M} \mathrm{Fe}-$ EDTA, and $500 \mu \mathrm{M}$ morpholineethanesulfonic acid-KOH, $\mathrm{pH}$ 5.5) and supplemented with 1\% Difco Agar Granulated (BD Biosciences), an agar which contains limited amounts of bioavailable nutrients. Pi-depleted media was prepared according to a previous study (Gruber et al. 2013). After pouring the media into 120 -by-120-mm square GREINER plates, a $2-\mathrm{cm}$ slide was cut out of the plates.

C. tofieldiae fungus was grown on PDA media at $25^{\circ} \mathrm{C}$ for at least 1 day. The chambers were illuminated by three fluorescent lamps (MITSUBISHI/OSRAM FL40 SS W/37). Two sterile metal beads were placed into 2-ml screw-lid tubes; then, $100 \mathrm{mg}$ of the fungus was excised with a sterile scalpel and added to the tubes. Excessive agar was removed by scratching it off with the scalpel. This step secured a high concentration of the fungal material and ensured that the suspension was not viscous. Afterward, $1 \mathrm{ml}$ of $10 \mathrm{mM}$ sterile $\mathrm{MgCl}_{2}$ was added, and the tubes were shaken intensely for $10 \mathrm{~min}$. After the homogenization, an additional $1 \mathrm{ml}$ of $\mathrm{MgCl}_{2}$ was added and the 
suspension was shaken again for $10 \mathrm{~min}$. The final concentration of fungal material in the suspension was $50 \mathrm{mg} / \mathrm{ml}$.

For the interaction experiment, stratified sterile Arabidopsis seed were used. With a pipette and sterile tips, $20 \mu \mathrm{l}$ of fungal suspension $(50 \mathrm{mg} / \mathrm{ml})$ was added to $250 \mu \mathrm{l}$ of seed in water for $5 \mathrm{~min}$, and washed twice with $1 \mathrm{ml}$ of $\mathrm{MgCl}_{2}(20 \mathrm{mM})$. By using a pipette with a cut sterile tip, the inoculated seed were transferred to the low-Pi and high-Pi plates.

For each condition (high and low Pi), four to five replicate plates with seven seeds were prepared. The seeds were placed on the edge of the removed agar slide so that the cotyledons had enough space to grow without being inhibited by the agar. The seven seeds were placed at fixed distances to allow uninhibited growth. In addition to the fungal plates, mock plates (negative control) were prepared which contained only $10 \mathrm{mM} \mathrm{MgCl}_{2}-$ washed seed. These plates were compared with the fungal plates. To keep the plates sterile, 3M Micropore tape was used. Finally, the plates were moved to the phytochambers where they were placed at a distance of one-plate width from each other. Every 4 days, the plates were shuffled to simulate naturally fluctuating light conditions.

The plates with Arabidopsis plants or fungi were grown under short-day conditions $\left(10 \mathrm{~h}\right.$ at $21^{\circ} \mathrm{C}$ and $14 \mathrm{~h}$ at $\left.19^{\circ} \mathrm{C}\right)$. Panasonic MLR-352-PE and Sanyo MLR-351 were used as phytochambers. The chambers were illuminated by three lamps on each side (OSRAM L36W/965, OSRAML 36W/865, or FL40SS 40/37) with an illuminance of 11,250 \pm 4,250 lux.

\section{RNA extraction and expression analysis by RT-qPCR.}

Total RNA extraction and RT-qPCR analysis were performed as described by Frerigmann and Gigolashvili (2014a) using intact seedlings. The relative quantification of expression levels was performed using the comparative $\Delta C$. tofieldiae method, and the calculated relative expression values were normalized to $P P 2 A$ and compared with the expression level in untreated WT plants $(\mathrm{Col}-0=1)$. If not specified in the figure legend, three technical replicates and three biological replicates from independently grown plants were analyzed (for primer sequences, see Supplementary Table S2).

\section{HPLC analysis of desulpho-GSL.}

The isolation and analysis of GSL content was performed using the desulpho-GSL method (Thies 1979) on an ultraperformance liquid chromatography device (Waters $\mathrm{GmbH}$ ), as described previously (Sewelam et al. 2014).

\section{GUS assay.}

Entire seedlings were homogenized with a ball and $500 \mu \mathrm{l}$ of precooled extraction buffer $(50 \mathrm{mM}$ Na-Pi buffer [pH 7], $1 \mathrm{mM}$ EDTA, and $0.1 \%$ [vol/vol] Triton X-100) for $2 \mathrm{~min}(20 / \mathrm{s}$ frequency), in a precooled TissueLyser. The crushed cells were centrifuged for $20 \mathrm{~min}$ at $4^{\circ} \mathrm{C}$, and soluble proteins were isolated for determination of GUS activity using 4-methylumbelliferyl- $\beta$-Dglucuronide as a substrate. The amount of 4-methylumbelliferone formed was recorded fluorometrically (excitation, $340 \mathrm{~nm}$; emission, $465 \mathrm{~nm}$ ). For this, $200 \mu \mathrm{l}$ of substrate buffer (protein extraction buffer with $1 \mathrm{mM}$ 4-methylumbelliferyl- $\beta$-D-glucuronide) and $25 \mu \mathrm{l}$ of protein extract were mixed, incubated at $37^{\circ} \mathrm{C}$ in the dark, and measured every 10 to $30 \mathrm{~min}$ on a multiwell plate reader. The slope of the increase in 4-methylumbelliferone was determined in the linear range and divided by the amount of protein.

\section{LITERATURE CITED}

Bates, T. R., and Lynch, J. P. 1996. Stimulation of root hair elongation in Arabidopsis thaliana by low phosphorus availability. Plant Cell Environ. 19:529-538.
Bednarek, P., Pislewska-Bednarek, M., Svatos, A., Schneider, B., Doubsky, J., Mansurova, M., Humphry, M., Consonni, C., Panstruga, R., SanchezVallet, A., Molina, A., and Schulze-Lefert, P. 2009. A glucosinolate metabolism pathway in living plant cells mediates broad-spectrum antifungal defense. Science 323:101-106.

Böttcher, C., Chapman, A., Fellermeier, F., Choudhary, M., Scheel, D., and Glawischnig, E. 2014. The biosynthetic pathway of indole-3carbaldehyde and indole-3-carboxylic acid derivatives in Arabidopsis. Plant Physiol. 165:841-853.

Cagnola, J. I., Cerdán, P. D., Pacín, M., Andrade, A., Rodriguez, V., Zurbriggen, M. D., Legris, M., Buchovsky, S., Carrillo, N., Chory, J., Blázquez, M. A., Alabadi, D., and Casal, J. J. 2018. Long-day photoperiod enhances jasmonic acid-related plant defense. Plant Physiol. 178:163-173

Chanclud, E., and Morel, J. B. 2016. Plant hormones: A fungal point of view. Mol. Plant Pathol. 17:1289-1297.

Chien, P. S., Chiang, C. P., Leong, S. J., and Chiou, T. J. 2018. Sensing and signaling of phosphate starvation: From local to long distance. Plant Cell Physiol. 59:1714-1722.

Clay, N. K., Adio, A. M., Denoux, C., Jander, G., and Ausubel, F. M. 2009. Glucosinolate metabolites required for an Arabidopsis innate immune response. Science 323:95-101.

Clough, S. J., and Bent, A. F. 1998. Floral dip: A simplified method for Agrobacterium-mediated transformation of Arabidopsis thaliana. Plant J. 16:735-743.

Cosme, M., Fernández, I., Van der Heijden, M. G. A., and Pieterse, C. M. J. 2018. Non-mycorrhizal plants: The exceptions that prove the rule. Trends Plant Sci. 23:577-587.

Crombez, H., Motte, H., and Beeckman, T. 2019. Tackling plant phosphate starvation by the roots. Dev. Cell 48:599-615.

Díaz-González, S., Marín, P., Sánchez, R., Arribas, C., Kruse, J., GonzálezMelendi, P., Brunner, F., and Sacristán, S. 2020. Mutualistic fungal endophyte Colletotrichum tofieldiae Ct0861 colonizes and increases growth and yield of maize and tomato plants. Agronomy (Basel) 10: 1493.

Dombrecht, B., Xue, G. P., Sprague, S. J., Kirkegaard, J. A., Ross, J. J., Reid, J. B., Fitt, G. P., Sewelam, N., Schenk, P. M., and Manners, J. M. 2007. MYC2 differentially modulates diverse jasmonate-dependent functions in Arabidopsis. Plant Cell 19:2225-2245.

Franco-Zorrilla, J. M., Valli, A., Todesco, M., Mateos, I., Puga, M. I., Rubio-Somoza, I., Leyva, A., Weigel, D., Garcia, J. A., and Paz-Ares, J. 2007. Target mimicry provides a new mechanism for regulation of microRNA activity. Nat. Genet. 39:1033-1037.

Frerigmann, H., and Gigolashvili, T. 2014a. Update on the role of R2R3MYBs in the regulation of glucosinolates upon sulfur deficiency. Front. Plant Sci. 5:626.

Frerigmann, H., and Gigolashvili, T. 2014b. MYB34, MYB51 and MYB122 distinctly deregulate indolic glucosinolate biosynthesis in Arabidopsis thaliana. Mol. Plant 7:814-828.

Fujii, H., Chiou, T. J., Lin, S. I., Aung, K., and Zhu, J. K. 2005. A miRNA involved in phosphate-starvation response in Arabidopsis. Curr. Biol. 15: 2038-2043.

Glawischnig, E., Hansen, B. G., Olsen, C. E., and Halkier, B. A. 2004. Camalexin is synthesized from indole-3-acetaidoxime, a key branching point between primary and secondary metabolism in Arabidopsis. Proc. Natl. Acad. Sci. U.S.A. 101:8245-8250.

Gruber, B. D., Giehl, R. F. H., Friedel, S., and von Wirén, N. 2013. Plasticity of the Arabidopsis root system under nutrient deficiencies. Plant Physiol. 163:161-179.

Hacquard, S., Kracher, B., Hiruma, K., Münch, P. C., Garrido-Oter, R., Thon, M. R., Weimann, A., Damm, U., Dallery, J.-F., Hainaut, M., Henrissat, B., Lespinet, O., Sacristán, S., Ver Loren van Themaat, E., Kemen, E., McHardy, A. C., Schulze-Lefert, P., and O'Connell, R. J. 2016. Survival trade-offs in plant roots during colonization by closely related beneficial and pathogenic fungi. Nat. Commun. 7:11362.

Halkier, B. A., and Gershenzon, J. 2006. Biology and biochemistry of glucosinolates. Annu. Rev. Plant Biol. 57:303-333.

Hillebrand, H., Bartling, D., and Weiler, E. W. 1998. Structural analysis of the nit2/nit1/nit3 gene cluster encoding nitrilases, enzymes catalyzing the terminal activation step in indole-acetic acid biosynthesis in Arabidopsis thaliana. Plant Mol. Biol. 36:89-99.

Hiruma, K., Fukunaga, S., Bednarek, P., Piślewska-Bednarek, M., Watanabe, S., Narusaka, Y., Shirasu, K., and Takano, Y. 2013. Glutathione and tryptophan metabolism are required for Arabidopsis immunity during the hypersensitive response to hemibiotrophs. Proc. Natl. Acad. Sci. U.S.A. 110:9589-9594.

Hiruma, K., Gerlach, N., Sacristán, S., Nakano, R. T., Hacquard, S., Kracher, B., Neumann, U., Ramírez, D., Bucher, M., O’Connell, R. J., 
and Schulze-Lefert, P. 2016. Root endophyte Colletotrichum tofieldiae confers plant fitness benefits that are phosphate status dependent. Cell 165:464-474.

Hopkins, R. J., van Dam, N. M., and van Loon, J. J. A. 2009. Role of glucosinolates in insect-plant relationships and multitrophic interactions. Annu. Rev. Entomol. 54:57-83.

Janowitz, T., Trompetter, I., and Piotrowski, M. 2009. Evolution of nitrilases in glucosinolate-containing plants. Phytochemistry 70:1680-1686.

Khan, G. A., Vogiatzaki, E., Glauser, G., and Poirier, Y. 2016. Phosphate deficiency induces the jasmonate pathway and enhances resistance to insect herbivory. Plant Physiol. 171:632-644.

Lahrmann, U., Strehmel, N., Langen, G., Frerigmann, H., Leson, L., Ding, Y., Scheel, D., Herklotz, S., Hilbert, M., and Zuccaro, A. 2015. Mutualistic root endophytism is not associated with the reduction of saprotrophic traits and requires a noncompromised plant innate immunity. New Phytol. 207:841-857.

Lehmann, T., Hoffmann, M., Hentrich, M., and Pollmann, S. 2010. Indole3-acetamide-dependent auxin biosynthesis: A widely distributed way of indole-3-acetic acid production? Eur. J. Cell Biol. 89:895-905.

Lehmann, T., Janowitz, T., Sanchez-Parra, B., Alonso, M. M. P., Trompetter, I., Piotrowski, M., and Pollmann, S. 2017. Arabidopsis NITRILASE 1 contributes to the regulation of root growth and development through modulation of auxin biosynthesis in seedlings. Front. Plant Sci. 8:15.

Lei, M. G., Zhu, C. M., Liu, Y. D., Karthikeyan, A. S., Bressan, R. A., Raghothama, K. G., and Liu, D. 2011. Ethylene signalling is involved in regulation of phosphate starvation-induced gene expression and production of acid phosphatases and anthocyanin in Arabidopsis. New Phytol. 189:1084-1095.

Lipka, V., Dittgen, J., Bednarek, P., Bhat, R., Wiermer, M., Stein, M., Landtag, J., Brandt, W., Rosahl, S., and Scheel, D. 2005. Pre-and postinvasion defenses both contribute to nonhost resistance in Arabidopsis. Science 310:1180-1183.

Liu, Y., Ahn, J.-E., Datta, S., Salzman, R. A., Moon, J., HuyghuesDespointes, B., Pittendrigh, B., Murdock, L. L., Koiwa, H., and ZhuSalzman, K. 2005. Arabidopsis vegetative storage protein is an anti-insect acid phosphatase. Plant Physiol. 139:1545-1556.

Lowder, L. G., Zhang, D., Baltes, N. J., Paul, J. W., 3rd, Tang, X., Zheng, X., Voytas, D. F., Hsieh, T. F., Zhang, Y., and Qi, Y. 2015. A CRISPR/Cas9 toolbox for multiplexed plant genome editing and transcriptional regulation. Plant Physiol. 169:971-985.

Lu, H., Zou, W. X., Meng, J. C., Hu, J., and Tan, R. X. 2000. New bioactive metabolites produced by Colletotrichum sp., an endophytic fungus in Artemisia annua. Plant Sci. 151:67-73.

Malka, S. K., and Cheng, Y. 2017. Possible interactions between the biosynthetic pathways of indole glucosinolate and auxin. Front. Plant Sci. 8:2131.

Mano, Y., and Nemoto, K. 2012. The pathway of auxin biosynthesis in plants. J. Exp. Bot. 63:2853-2872.

Maor, R., Haskin, S., Levi-Kedmi, H., and Sharon, A. 2004. In planta production of indole-3-acetic acid by Colletotrichum gloeosporioides f. sp. aeschynomene. Appl. Environ. Microbiol. 70:1852-1854.

Muchhal, U. S., Pardo, J. M., and Raghothama, K. G. 1996. Phosphate transporters from the higher plant Arabidopsis thaliana. Proc. Natl. Acad. Sci. U.S.A. 93:10519-10523.

Nacry, P., Canivenc, G., Muller, B., Azmi, A., Van Onckelen, H., Rossignol, M., and Doumas, P. 2005. A role for auxin redistribution in the responses of the root system architecture to phosphate starvation in Arabidopsis. Plant Physiol. 138:2061-2074.

Normanly, J., Grisafi, P., Fink, G. R., and Bartel, B. 1997. Arabidopsis mutants resistant to the auxin effects of indole-3-acetonitrile are defective in the nitrilase encoded by the NIT1 gene. Plant Cell 9:1781-1790.

Numponsak, T., Kumla, J., Suwannarach, N., Matsui, K., and Lumyong, S. 2018. Biosynthetic pathway and optimal conditions for the production of indole-3-acetic acid by an endophytic fungus, Colletotrichum fructicola CMU-A109. PLoS One 13:e0205070.

Pant, B. D., Pant, P., Erban, A., Huhman, D., Kopka, J., and Scheible, W. R. 2015. Identification of primary and secondary metabolites with phosphorus status-dependent abundance in Arabidopsis, and of the transcription factor PHR1 as a major regulator of metabolic changes during phosphorus limitation. Plant Cell Environ. 38:172-187.

Parniske, M. 2008. Arbuscular mycorrhiza: The mother of plant root endosymbioses. Nat. Rev. Microbiol. 6:763-775.

Pastorczyk, M., and Bednarek, P. 2016. The function of glucosinolates and related metabolites in plant innate immunity. Adv. Bot. Res. 80:171-198.

Pastorczyk, M., Kosaka, A., Piślewska-Bednarek, M., López, G., Frerigmann, H., Kułak, K., Glawischnig, E., Molina, A., Takano, Y., and Bednarek, P. 2020. The role of CYP71A12 monooxygenase in pathogentriggered tryptophan metabolism and Arabidopsis immunity. New Phytol. 225:400-412.

Péret, B., Clément, M., Nussaume, L., and Desnos, T. 2011. Root developmental adaptation to phosphate starvation: Better safe than sorry. Trends Plant Sci. 16:442-450.

Pérez-Torres, C.-A., López-Bucio, J., Cruz-Ramírez, A., Ibarra-Laclette, E., Dharmasiri, S., Estelle, M., and Herrera-Estrella, L. 2008. Phosphate availability alters lateral root development in Arabidopsis by modulating auxin sensitivity via a mechanism involving the TIR1 auxin receptor. Plant Cell 20:3258-3272.

Pfalz, M., Mikkelsen, M. D., Bednarek, P., Olsen, C. E., Halkier, B. A., and Kroymann, J. 2011. Metabolic engineering in Nicotiana benthamiana reveals key enzyme functions in Arabidopsis indole glucosinolate modification. Plant Cell 23:716-729.

Prerostova, S., Kramna, B., Dobrev, P. I., Gaudinova, A., Marsik, P., Fiala, R., Knirsch, V., Vanek, T., Kuresova, G., and Vankova, R. 2018. Organ-specific hormonal cross-talk in phosphate deficiency. Environ. Exp. Bot. 153:198-208.

Robinson, M., Riov, J., and Sharon, A. 1998. Indole-3-acetic acid biosynthesis in Colletotrichum gloeosporioides f. sp. aeschynomene. Appl. Environ. Microbiol. 64:5030-5032.

Sanchez-Vallet, A., Ramos, B., Bednarek, P., Lopez, G., PislewskaBednarek, M., Schulze-Lefert, P., and Molina, A. 2010. Tryptophanderived secondary metabolites in Arabidopsis thaliana confer non-host resistance to necrotrophic Plectosphaerella cucumerina fungi. Plant J. 63:115-127.

Sewelam, N., Jaspert, N., Van Der Kelen, K., Tognetti, V. B., Schmitz, J., Frerigmann, H., Stahl, E., Zeier, J., Van Breusegem, F., and Maurino, V. G. 2014. Spatial $\mathrm{H}_{2} \mathrm{O}_{2}$ signalling specificity: $\mathrm{H}_{2} \mathrm{O}_{2}$ from chloroplasts and peroxisomes modulates the plant transcriptome differentially. Mol. Plant 7:1191-1210.

Song, S., Huang, H., Gao, H., Wang, J., Wu, D., Liu, X., Yang, S., Zhai, Q., Li, C., Qi, T., and Xie, D. 2014. Interaction between MYC2 and ETHYLENE INSENSITIVE3 modulates antagonism between jasmonate and ethylene signaling in Arabidopsis. Plant Cell 26:263-279.

Thies, W. 1979. Detection and utilization of a glucosinolate sulfohydrolase in the edible snail, Helix pomatia. Naturwissenschaften 66:364-365.

Ulmasov, T., Murfett, J., Hagen, G., and Guilfoyle, T. J. 1997. Aux/IAA proteins repress expression of reporter genes containing natural and highly active synthetic auxin response elements. Plant Cell 9:1963-1971.

Vorwerk, S., Biernacki, S., Hillebrand, H., Janzik, I., Müller, A., Weiler, E. W., and Piotrowski, M. 2001. Enzymatic characterization of the recombinant Arabidopsis thaliana nitrilase subfamily encoded by the NIT2/NIT1/NIT3-gene cluster. Planta 212:508-516.

Vos, I. A., Moritz, L., Pieterse, C. M. J., and Van Wees, S. C. M. 2015. Impact of hormonal crosstalk on plant resistance and fitness under multiattacker conditions. Front. Plant Sci. 6:639.

Wittstock, U., Kurzbach, E., Herfurth, A. M., and Stauber, E. J. 2016. Glucosinolate breakdown. Adv. Bot. Res. 80:125-169.

Zarei, A., Korbes, A. P., Younessi, P., Montiel, G., Champion, A., and Memelink, J. 2011. Two GCC boxes and AP2/ERF-domain transcription factor ORA59 in jasmonate/ethylene-mediated activation of the PDF1.2 promoter in Arabidopsis. Plant Mol. Biol. 75:321-331.

Zhao, Y., Hull, A. K., Gupta, N. R., Goss, K. A., Alonso, J., Ecker, J. R., Normanly, J., Chory, J., and Celenza, J. L. 2002. Trp-dependent auxin biosynthesis in Arabidopsis: Involvement of cytochrome P450s CYP79B2 and CYP79B3. Genes Dev. 16:3100-3112. 